\title{
House price dynamics and their reaction to macroeconomic changes
}

Article

Accepted Version

Nneji, O., Brooks, C. and Ward, C. W.R. (2013) House price dynamics and their reaction to macroeconomic changes. Economic Modelling, 32. pp. 172-178. ISSN 0264-9993 doi: https://doi.org/10.1016/j.econmod.2013.02.007 Available at https://centaur.reading.ac.uk/31493/

It is advisable to refer to the publisher's version if you intend to cite from the work. See Guidance on citing.

To link to this article DOI: http://dx.doi.org/10.1016/j.econmod.2013.02.007

Publisher: Elsevier

All outputs in CentAUR are protected by Intellectual Property Rights law, including copyright law. Copyright and IPR is retained by the creators or other copyright holders. Terms and conditions for use of this material are defined in the End User Agreement.

\section{www.reading.ac.uk/centaur}

\section{CentAUR}

Central Archive at the University of Reading

Reading's research outputs online 
NOTICE: this is the author's version of a work that was accepted for publication in Economic Modelling. Changes resulting from the publishing process, such as peer review, editing, corrections, structural formatting, and other quality control mechanisms may not be reflected in this document. Changes may have been made to this work since it was submitted for publication. A definitive version was subsequently published in Economic Modelling, 32 (2013), DOI: 10.1016/j.econmod.2013.02.007 


\title{
House Price Dynamics and Their Reaction to Macroeconomic Changes
}

\author{
Ogonna Nneji \\ ICMA Centre, University of Reading \\ Chris Brooks \\ ICMA Centre, University of Reading \\ Charles Ward \\ ICMA Centre, University of Reading
}

February 2013

\begin{abstract}
This article applies a three-regime Markov switching model to investigate the impact of the macroeconomy on the dynamics of the residential real estate market in the US. Focusing on the period between 1960 and 2011, the methodology implemented allows for a clearer understanding of the drivers of the real estate market in "boom", "steady-state" and "crash" regimes. Our results show that the sensitivity of the real estate market to economic changes is regimedependent. The paper then proceeds to examine whether policymakers are able to influence a regime switch away from the crash regime. We find that a decrease in interest rate spreads could be an effective catalyst to precipitate such a change of state.
\end{abstract}

Key words: house prices, monetary policy, Markov switching model, macroeconomic drivers JEL codes: G12, R31

Acknowledgement: the authors are grateful to two anonymous referees for their helpful comments on a previous version of this paper.

Contact:

Chris Brooks

ICMA Centre

University of Reading

Whiteknights

Reading RG6 6BA,

UK

E-mail: $\underline{\text { C.Brooks@.rdg.ac.uk }}$

Tel: +44118 3787809

Fax: +44 1189314741 


\section{Introduction}

Over the last few decades, residential property markets in many industrialised nations across the globe have witnessed large cyclical variations in prices and volumes. Real estate cycles are often characterised by a surge in prices followed by a fall or crash. An example of this was seen in the UK housing market in the late 1980s. Financial liberalization in the UK led to a price boom, but following an increase in interest rates, residential prices experienced a sharp decline in the early 1990s. More recently in the US, nationwide property prices grew by over $61 \%$ between 2000 and 2005 but fell sharply by 38\% in the four years that followed. There are similar examples in other countries including Japan, Ireland and Spain. These cycles are often linked with changes in macroeconomic drivers such as interest rates and economic growth.

This cyclical nature of the residential real estate market has been a major topic of discussion over the years mainly because a large proportion of the average household's wealth is invested in property. The housing market in the US accounts for more than 50\% of the country's fixed capital stock (Baffoe-Bonnie, 1998). Economic theory suggests that wealth is one of the key drivers of aggregate consumption in any economy, and so therefore, a downturn in the housing market is likely to be followed by a decrease in household consumption levels, which may in turn have adverse effects on the growth rate of an economy. Empirical evidence of this is shown in Case et al. (2001), who use a panel of 14 countries in their study to present statistical evidence that a $10 \%$ rise in housing wealth would lead to a $1.1 \%$ increase in consumption.

The behaviour of the residential real estate market is also important because of the impact of house price falls on the lending portfolios of commercial banks and other financial institutions. Wheelock (2006) shows that a period of large declines in house prices is very often followed by an increase in the rate of mortgage defaults, which has an adverse effect on banks' profits. The reduction in profitability may lead to failures in banks and other real estate lenders and a subsequent slowdown in economic activity. A recent high profile example of this was the collapse of Lehman Brothers which was heavily exposed to the real estate market via mortgage backed securities. Following the failure of Lehmans in September 2008, the CBOE Volatility Index (VIX), often referred to as the "fear index", jumped 70\%, and a global recession followed shortly thereafter. In their empirical study, Ghent and Owyang (2010) provide evidence that house price changes drive business cycles. Thus, given the potentially detrimental effects of

${ }^{1}$ Whaley (2000) concludes that the VIX index is a gauge for investors' fears as it provides an aggregate view of their expectations of volatility in the stock market. 
declining housing prices on the economy, a deeper understanding of the economic drivers of the residential real estate market is required.

The purpose of this paper is to investigate how changes in key macroeconomic variables could influence the growth in house prices, depending on which part of the cycle the real estate market is in. This study examines the impact of macroeconomic drivers of real estate price changes in a three-regime-switching context, thus providing information on how selected economic factors influence price changes in the residential real estate market depending on whether the housing market is a "boom", "steady-state" or "crash" regime. The paper further contributes to the existing literature by investigating the likelihood of monetary policy tools precipitating a switch from a crash regime.

Most prior studies on this topic do not allow for significant structural breaks in house prices resulting from huge upswings and collapses in prices, instead assuming that the relationship between house prices and economic variables is stable and consistent. The sensitivity of house prices to changes in these variables could, however, depend on the stage in the housing cycle. Failing to account specifically for volatile periods such as the period between 2000 and 2012 in the US housing market could produce results which may not reflect a true picture of the relationship between macro factors and growth in house prices. Xiao (2007) and Nneji et al. (2013a), studying the residential property market in Hong Kong and the US respectively, provide evidence that structural breaks in real estate prices caused by speculative bubbles are likely to disconnect the housing market from the cost of renting. As a result, the relationship between the housing market and its macroeconomic determinants may be regime-varying, and so accounting for the housing market cycle is critical when examining its response to external macroeconomic factors. We seek to address several policy-relevant questions in this research. First, is the housing market more sensitive to economic changes in boom or bust periods? Second, which economic factor(s) has(have) the strongest impact on the housing market in each regime or cycle? Third, is it possible for policymakers to influence a switch away from the "bust" state (typically characterised by negative growth) using monetary policy tools?

Studying the US housing market between 1960 and 2011, we apply a three state Markov switching model to examine the possibility that macroeconomic drivers of house price changes are regime-specific. The regime-switching methodology implemented in this paper also enables us to identify cycles in the housing market. We can then evaluate whether policymakers are able to switch the housing market from a crash regime to a steady state simply by using monetary policy tools. To our knowledge, this is the first study that applies a three Markov switching 
model in the context of the relationship between the real estate market and the macroeconomy, and the first study that examines the efficacy of policy tools for causing a switch away from the "crash" regime.

The layout of the rest of the paper is as follows. Section 2 is dedicated to reviewing the existing literature on the relationship between economic variables and the residential real estate market. The following section, Section 3, provides descriptive statistics for the data used in the paper. In Section 4 a more detailed explanation of the methodologies implemented is given. Section 5 interprets and discusses the results from the Markov switching regressions, and in Section 6 we examine the power of monetary policy tools in influencing a switch in the housing market from a crash regime. We conclude in Section 7.

\section{Literature Review}

The literature on the macroeconomic determinants of house prices is vast. For many years, especially before the subprime mortgage market crisis of the late 2000s, researchers used linear models to examine the relationship between the macroeconomy and the dynamics of house prices. These papers have generally applied regression analyses to evaluate how growth in real estate prices is being driven by economic factors including interest rates, inflation, the unemployment rate, economic growth.

The majority of these papers identify interest rates as the most important explanatory variable. One early study is Abraham and Hendershott (1992). Using pooled cross-sectional data on metropolitan house prices in the US between 1977 and 1991, they find that macroeconomic factors including interest rates and employment are significant in influencing house prices. Iacoviello and Minetti (2003) argue that, over time, house prices became more sensitive to interest rate changes due to financial liberalization in European countries including the UK. More recently, this sentiment is shared by Himmelberg et al. (2005), who show the importance of interest rates to house price changes. The authors also find that the sensitivity of house prices to long-term interest rates intensifies when rates had been relatively low in the recent past. Furthermore, they cite that house prices are even more sensitive to long-term interest rates in cities where values grow relatively faster. Adams and Füss (2010) distinguish the impact of short term from long term interest rates on real estate price dynamics. They argue that short term interest rates adversely affect demand for houses mainly because of the effect on mortgage rates and the cost of financing for construction firms. Holly and Jones (1997), McQuinn and O'Reilly 
(2007) and Bouchouicha and Ftiti (2012) have also investigated the link between the real estate market and interest rates.

Other papers have established that price dynamics in the real estate market may be influenced by macroeconomic factors other than interest rates. For example, Lastrapes (2002), using a vector autoregressive model, attributes short run increases in house prices to positive money shocks. Brunnermeier and Julliard (2008) conclude that inflation, not real interest rate changes, influences the price-rent ratio as it is a signal of a likely future downturn in the economy. Investigating the linkage between macroeconomic fluctuations and international house prices, Beltratti and Morana (2009) estimate that $40 \%$ of the variation in house prices in G-7 countries is caused by global macroeconomic shocks. The study by Adams and Füss (2010) provides evidence that variables linked with economic activity such as industrial production, the level of unemployment and money supply influence demand for housing and house price. Other papers that study the macroeconomy-housing relationship on an international scale include Englund and Iaonnides (1997), Tsatsaronis and Zhu (2004) and Glindro et al. (2011).

As discussed above, only a handful of studies have accounted for the housing cycle when examining the relationship between house prices and the macroeconomy. A notable exception is the research by Hall et al. (1997), who use a two-regime switching error-correction approach to develop a macroeconomic model for UK house prices which accounts for booms and busts. Their paper uses a Markov regime-switching approach, assuming that there are only two distinct regimes in the housing market - "boom" and "bust". The present paper adds a third regime which we call "steady-state" based on the premise that the US housing market may have been in a dormant state where prices are growing at a small steady rate. In this state, the housing market is neither booming nor declining in prices. This can be observed in the early 1990s where nominal house prices grew by an average of just 3\% per annum in contrast to the early 2000s boom of $11 \%$ annual growth and the late 2000s bust which saw prices decline by an average of $6 \%$ per year. Furthermore, this study builds on the work by Hall et al. as we model the government's ability to affect a regime shift, which thus has policy implications.

\section{Data}

The data employed in this study consist of sets of 203 quarterly observations from 1960Q1 to 2011Q3. For residential property market prices, the data are supplied by the Lincoln Institute of Land Policy, constructed using the methodology of Davis et al. (2008). In order to compute this 
series, Davis et al. use interpolation procedures to adjust the quarterly changes in the Freddie Mac Conventional Mortgage House Price Index (CMHPI) in order to connect the series with the Decennial Census of Housing benchmark levels. The price series used in this study is adjusted for inflation.

In this paper, we employ inflation, disposable income growth, the short rate and the term structure of interest rates (also referred to as the yield curve or interest rate spread) as key economic variables that influence housing demand. These variables have been selected because of their significant contribution to the dynamics of house prices suggested in the literature. For example, studying the effect of economic risk factors on growth in the US commercial real estate market, Ling and Naranjo (1997) identify unexpected inflation, yield spread and the Treasury bill rate as its key drivers. Similarly, the study by Brooks and Tsolacos (1999) shows that the term structure and unexpected inflation explain changes in the UK property market. Englund and Ioannides (1997) find that lagged interest rate and influences house price dynamics in 15 OECD countries. Using a life-cycle model of the property market, Ortalo-Magne and Rady (2006) show that house price dynamics are driven by disposable income.

These drivers are likely to have the following impacts on real estate prices. An increase in the rate of interest is expected to drive borrowing rates up, thus increasing the cost of servicing mortgages. This would, in turn, lead to a decrease in demand for properties and a subsequent fall in prices. Rising interest rates might additionally be expected to lead to an increase in the number of defaults on mortgages (especially adjustable-rate mortgages), which could also lead to a fall in prices. An increase in the term structure means that the gap between long and short term rates widens. When this happens, market agents would expect future increases in the short term interest rate and so house prices may fall. In addition, most housing finance is arranged at the long maturity end, and thus upward twists in the yield curve will also lead to rises in borrowing costs for mortgage holders. Growth in disposable income is expected to have a positive impact on the housing market whilst the effect of inflation on the market should be negative.

The explanatory variables are constructed as follows. The short term rate used is the yield on 3month US Treasury bills. The disposable personal income measure used in the paper is obtained from the US Bureau of Economic Analysis. It is the proportion of income available to individuals for spending after deducting personal current taxes. The term structure is constructed by taking the difference between the long rate and the short rate. We take the constant maturity rate on 10-year Treasuries as a proxy for the long interest rate. The inflation rate is computed from the Consumer Price Index (CPI) series. The economic data series are retrieved from the 
online database of the Federal Reserve Bank of St. Louis. ${ }^{2}$ A set of summary statistics for our sample is presented in Table 1.

Table 1: Summary Statistics

Here, HP, CPI, INC, LTR, STR and TS are acronyms for house prices, the consumer price index, disposable income, long term interest rates, short term interest rates and the term structure, respectively. The symbol " $\Delta$ " represents the percentage changes in the series. Note that the data series for house prices and interest rates are adjusted for inflation.

\begin{tabular}{ccccccc}
\hline & $\Delta$ HP & $\Delta$ CPI & $\Delta$ INC & LTR & STR & TS \\
\hline Mean & $0.29 \%$ & $0.98 \%$ & $0.54 \%$ & $5.67 \%$ & $4.72 \%$ & $0.95 \%$ \\
Maximum & $4.53 \%$ & $3.80 \%$ & $4.33 \%$ & $13.40 \%$ & $13.54 \%$ & $3.35 \%$ \\
Minimum & $-8.30 \%$ & $-2.38 \%$ & $-2.55 \%$ & $1.67 \%$ & $-0.88 \%$ & $-1.94 \%$ \\
Skewness & -1.86 & 0.67 & -0.02 & 1.14 & 0.67 & 0.05 \\
Kurtosis & 8.95 & 5.98 & 5.23 & 4.16 & 4.15 & 2.58 \\
\hline
\end{tabular}

The descriptive statistics on house prices, CPI and INC are the percentage changes of these series, thus representing the house price growth rate, inflation rate and disposable income growth rate, respectively. From the table, it is clear that the average real growth in house prices is a modest $0.29 \%$ per quarter or $1.17 \%$ per annum. Prices have grown as much as $4.53 \%$ during the boom years, whilst in market downturns such as the recent crash, price falls have been more severe $(-8.30 \%)$. The distribution of returns on investing in the housing market is negatively skewed, thus implying that it has a longer left tail. Another key factor to note is that the distribution of house price growth is leptokurtic (i.e. kurtosis greater than 3), which implies that the data are highly concentrated around the mean. The second column refers to the percentage changes in CPI, i.e. the inflation rate. From our sample, the average quarterly rate of inflation is $0.98 \%$, which equates to an annual inflation rate of almost $4 \%$. The real growth in disposable income, denoted by the percentage change in INC, has an average of $0.54 \%$ per quarter or $2.16 \%$ per year. The greatest drop in income in our sample set is $-2.55 \%$, occurring at the end of 2008, which was fuelled by the economic decline caused by the "meltdown" of the subprime mortgage market. The early 1980s saw the highest short and long term interest rates, $13.40 \%$ and $13.54 \%$, respectively. As for the term structure, it has an average of $0.95 \%$ and a maximum of $3.35 \%$.

\section{Methodology}

\footnotetext{
${ }^{2}$ For more information on the original sources of the data, see the website of the Federal Reserve Bank of St. Louis: http://www.research.stlouisfed.org/
} 
As stated earlier in this paper, most of the studies that have attempted to examine the relationship between economic variables and the real estate market (either commercial or residential) have used linear regression type models. For example, Levin and Wright (1997) use a pooled cross-sectional regression approach to regress house prices on several explanatory variables including real interest rates while Hort (1998) applies an error correction model to study the impact of demand and supply-based market fundamentals on house prices in Sweden. Other examples include the papers reviewed in Section 2.

Building on from these studies, in this paper, we apply a three-regime univariate Markov switching (MS) model due to Hamilton $(1989,1994)$. This methodology allows us to study the nonlinear relationship between the growth in house prices and changes to economic fundamentals:

$$
\Delta H P_{t}=\beta_{S_{t}, 0}+\beta_{S_{t-1}, 1} \Delta S T R_{t-1}+\beta_{S_{t-1}, 2} \Delta T S_{t-1}+\beta_{S_{t-1}, 3} \Delta C P I_{t-1}+\beta_{S_{t-1}, 4} \Delta I N C_{t-1}+\varepsilon_{S_{t}}
$$

where $\varepsilon_{S_{t}, t} \sim N\left(0, \sigma_{S_{t}}^{2}\right)$ and $S_{t}=i($ for $i=1,2$ or 3$)$

The estimated betas from model (1) can be interpreted as a measure of the sensitivity of house price growth to changes in the interest rate, term structure, inflation and disposable income. Notice that these explanatory variables are lagged and not contemporaneous because, unlike other asset classes such as the stock market, changes in the economy are expected to have a delayed effect on the housing market. This formulation also avoids the possible concern that there may potentially be an endogeneity problem if there are feedbacks from the housing market to the macroeconomy or if house price dynamics affect monetary policy. We assume the lag time to be one quarter.

Our model is a three-regime MS model, where the term $S_{t}$ is the latent state variable which could take the value of 1,2 or 3 depending on the state or regime in the housing market. In other words, the effect of each of the explanatory economic variables depends on the housing cycle i.e. whether there is a boom, bust or steady growth in the housing market. This unobservable state variable is governed by a first order Markov chain with a constant transition probability matrix (P):

$\mathrm{P}=\left[\begin{array}{lll}\operatorname{Pr}\left(S_{t}=1 \mid S_{t-1}=1\right) & \operatorname{Pr}\left(S_{t}=2 \mid S_{t-1}=1\right) & \operatorname{Pr}\left(S_{t}=3 \mid S_{t-1}=1\right) \\ \operatorname{Pr}\left(S_{t}=1 \mid S_{t-1}=2\right) & \operatorname{Pr}\left(S_{t}=2 \mid S_{t-1}=2\right) & \operatorname{Pr}\left(S_{t}=3 \mid S_{t-1}=2\right) \\ \operatorname{Pr}\left(S_{t}=1 \mid S_{t-1}=3\right) & \operatorname{Pr}\left(S_{t}=2 \mid S_{t-1}=3\right) & \operatorname{Pr}\left(S_{t}=3 \mid S_{t-1}=3\right)\end{array}\right]=\left[\begin{array}{lll}p_{11} & p_{12} & p_{13} \\ p_{21} & p_{22} & p_{23} \\ p_{31} & p_{32} & p_{33}\end{array}\right]$

where $p_{i j}$ are the transition probabilities from state $i$ to state $j$. 
The MS model is estimated using a maximum likelihood procedure. Under the assumption that the error term $\left(\varepsilon_{t}\right)$ is normally distributed, the density of $y_{t}$ conditional on the regime $(i)$ is represented as:

$\eta_{i, t}=f\left(y_{t} \mid S_{t}=i, X_{t}, \Omega_{t-1} ; \theta\right)=\frac{1}{\sqrt{2 \pi \sigma_{i}^{2}}} \exp \left\{-\frac{\left(y_{t}-X_{t-1}^{\prime} \beta_{i}\right)^{2}}{2 \sigma_{i}^{2}}\right\}$

where, $\Omega_{t-1}=\left(y_{t-1}, y_{t-2}, \ldots, X_{t-1}, X_{t-2}, \ldots\right)$ represents all the past information to time $t-1, \theta$ is the vector of parameters $\left(\beta_{S_{t}, 0}, \beta_{S_{t}, 1}, \beta_{S_{t}, 2}, \beta_{S_{t}, 3}, \beta_{S_{t}, 4}, \sigma_{S_{t}}^{2}, p_{00}, p_{11}, p_{22}\right)^{\prime}$ to be estimated. Note that $y_{t}$ is the dependent variable while $X_{t}^{\prime}$ is the vector of explanatory variables. The conditional density of the observation at time $t$ is obtained from the joint density of $y_{t}$ and $S_{t}$ :

$f\left(y_{t} \mid \Omega_{t-1} ; \theta\right)=f\left(y_{t}, S_{t}=1 \mid \Omega_{t-1} ; \theta\right)+f\left(y_{t}, S_{t}=2 \mid \Omega_{t-1} ; \theta\right)+f\left(y_{t}, S_{t}=3 \mid \Omega_{t-1} ; \theta\right)$

which is equivalent to:

$\sum_{i=1}^{3} f\left(y_{t} \mid S_{t}=i, \Omega_{t-1} ; \theta\right) P\left(S_{t}=i \mid \Omega_{t-1} ; \theta\right)$

As it is impossible to know for certain what regime the housing market is in, inference about the regime is made by observing the growth rate of house prices. The inference comes in the form of filtered probabilities $\left(\xi_{j t}\right)$, which are computed recursively using historical information, $\Omega_{t-1}$ :

$\xi_{j t}=\operatorname{Pr}\left(S_{t}=j \mid \Omega_{t} ; \theta\right)=\frac{\sum_{i=1}^{3} p_{i j} \xi_{i, t-1} \eta_{j t}}{f\left(y_{t} \mid \Omega_{t-1} ; \theta\right)}$

These filtered probabilities depend on real-time updated information up to time $t$. It is also interesting to compute probabilities of what state/regime the housing market was in at a previous date $t$ using all the observations and information obtained through a later date $T$. These are known as smoothed probabilities $\left(\xi_{i t \mid T}=\operatorname{Pr}\left(S_{t}=i \mid \Omega_{T} ; \theta\right)\right)$, and they are computed using an algorithm developed by Kim (1994). Estimation of the parameters $\theta$ in the MS model is done by maximizing the following log-likelihood function:

$1(\theta)=\sum_{t=1}^{T} f\left(y_{t} \mid \Omega_{t-1} ; \theta\right)$ 


\section{Results}

Before applying the three-regime MS model, we examine the same regression in equation (1) for the whole period using a standard linear ordinary least squares (OLS) estimation procedure. In this OLS model, the subscript $S_{t}$ is omitted from the right hand side variables of the equation. Note that the estimated coefficients are standardised following the approach introduced by Bring (1994). This allows us to determine the relative importance of the selected explanatory variable, thereby making it easier to interpret the output from the OLS model. The results are shown in Table 2.

\section{Table 2: OLS Model Output}

We present a linear regression model of equation (1) for a single regime using ordinary least squares estimation procedure. This time series regression analysis is performed on the whole sample between 1960 and 2011. The dependent variable is the quarterly change in house prices and the independent variables are the changes in the short term interest rate $(\Delta \mathrm{SR})$, the term spread $(\Delta \mathrm{TS})$, inflation rates $(\Delta \mathrm{CPI})$, and disposable income $(\Delta \mathrm{INC})$. The figures in parentheses are the p-values and the grey shade indicates variables that are statistically significant $(10 \%$ at least).

\begin{tabular}{cccccc}
\hline & Constant & $\Delta$ SR & $\Delta$ TS & $\Delta$ CPI & $\Delta$ INC \\
\hline \multirow{2}{*}{$\beta$} & -0.0020 & -0.2283 & -0.1935 & -0.0389 & 0.1645 \\
& $(0.35)$ & $(0.01)$ & $(0.03)$ & $(0.58)$ & $(0.02)$ \\
\hline
\end{tabular}

In this linear single state model, the sign of the short term interest rate is negative and it is statistically significant, implying that an increase in the rate of interest would have a negative effect on house prices, as expected. The term structure is also negative as anticipated and it is a statistically significant driver of house price dynamics. The inflation rate parameter estimate is positive but statistically insignificant. Growth in disposable income, however, does have a relatively large and positive beta, which implies that an increase in disposable income is expected to have the most significant positive effect on house prices of all the economic variables investigated. These results raise crucial questions, such as whether it is really true that the inflation rate has no effect on real house prices, and also, whether it is the case that the sensitivity of the housing market to economic changes remains constant between different regimes. Implementing the three-regime MS model provides answers to these questions.

Table 3: Determining the appropriate number of regimes using information criteria In this table, we compare the Akaike (AIC), Hannan-Quinn (HQIC) and Schwartz (SIC) information criterion to determine the optimal number of regimes to be used to model house price changes. 


\begin{tabular}{ccccc}
\hline Information Criterion & 1 Regime & 2 Regimes & 3 Regimes & 4 Regimes \\
\hline AIC & -5.2731 & -6.1473 & -6.4518 & -6.4652 \\
HQIC & -5.2403 & -6.0424 & -6.2748 & -6.2029 \\
SIC & -5.1920 & -5.8880 & -6.0142 & -6.0142 \\
\hline
\end{tabular}

Note that in order to prove that the statistically appropriate number of regimes is three, we observe and compare the Hannan-Quinn, Akaike and Schwarz information criteria of two-, three- and four-regime versions of the MS model. A two-regime model would imply that there is just a "boom" and "bust" state while a four-regime model would signify a "crash", "boom", "slow growth" and "recovery" (Ryden et al., 1998 and Guidolin and Timmermann, 2008). In our case, we find that the Hannan-Quinn and Schwarz information criteria using all the different regime approaches are smallest in the three-regime Markov Switching model, thus we infer that the optimal number of regimes to be used is three: "boom", "steady-state" and "bust". This is shown in Table 3. AIC selects four regimes, but the criterion value is only slightly higher for the three-regime model; we consider four regimes to represent an over-parameterisation of the data, and therefore we implement the three-regime approach. The table also highlights the inadequacy of the linear model specification, since the values of all three information criteria are far inferior for the 1-regime (i.e. linear) model than for any of the switching models.

Prior to discussing the estimated regime-dependent betas, it is important to view and discuss the estimated smoothed probabilities of the housing market being in any of these growth regimes. These probabilities allow us to make statistical inferences about the regime in which the housing market resides at each point in time by observing the complete dataset. Recall, the smoothed probabilities are dependent on the estimated transition probability matrix which provides information on the probability of a switch from one state at time $t-1$ to another at time $t$ as depicted in equation (2). The estimated transition probability matrix is shown in equation (8):

$$
\mathrm{P}=\left[\begin{array}{lll}
p_{11} & p_{12} & p_{13} \\
p_{21} & p_{22} & p_{23} \\
p_{31} & p_{32} & p_{33}
\end{array}\right]=\left[\begin{array}{lll}
0.953 & 0.025 & 0.039 \\
0.047 & 0.951 & 0.000 \\
0.000 & 0.024 & 0.960
\end{array}\right]
$$

where 1 = Steady-State, $2=$ Boom and $3=$ Crash regime.

The probability of remaining in the crash regime given that the housing market was in the crash regime in the previous period is $96 \%$, meaning that this is the most persistent regime in the housing market over the last 50 years. There is a $2 \%$ chance of switching from the steady-state 
regime to the boom regime, whilst there is a 3.9\% chance of a transition to a crash regime when prices are growing steadily. The boom regime has the least persistence in that there is a $95.1 \%$ probability of remaining in the boom period if there was a boom in the last quarter. With these transition probabilities, it is also possible to compute the expected duration (ED) of being in each of the regimes. This is simply calculated using the following formula:

$$
E D=1 /\left(1-p_{i i}\right)
$$

Therefore, the expected duration of being in the steady-state, boom and crash regimes are roughly 21, 20 and 25 quarters, respectively. This means that we would expect a steady growth and housing boom regimes to last for five years and a housing bust last for just over six years. A graphical representation of the smoothed probabilities is given in Figure 1.

Figure 1: House price dynamics and regimes

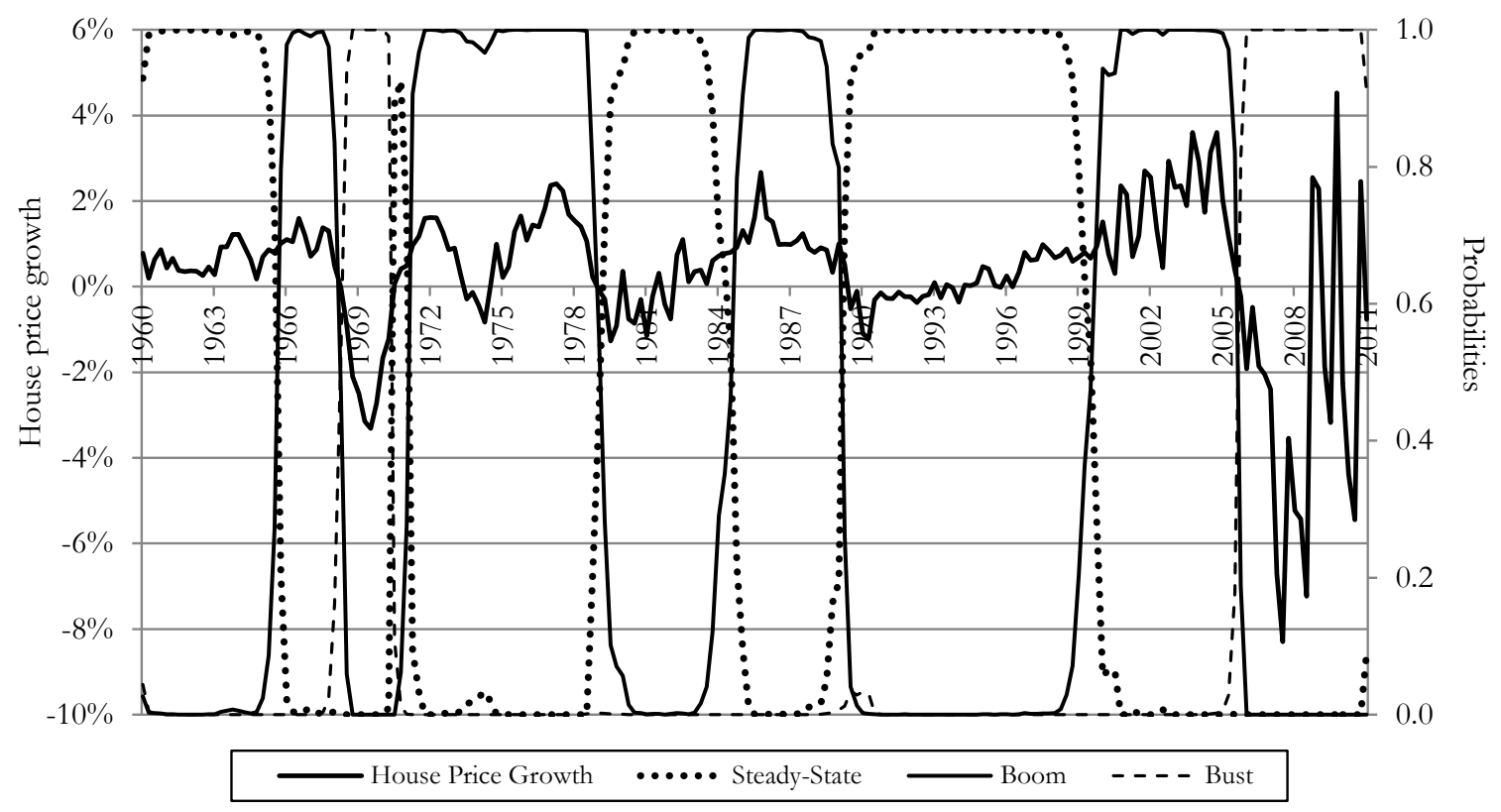

From Figure 1, we note that the dominant state is as expected steady-state although the stability of the market is quite clearly disturbed by the policy changes that took place in the 2000s. It is clear that in the 1960s, real house prices grew at a steady pace of below $2 \%$ per quarter, until the market witnessed a dip. This dip coincided with the 11 month recession of the late 1960s as noted by the National Bureau of Economic Research. However, the housing market soon returned to its steady state and then a boom as prices picked up in the early 1970s. This lasted 
until towards the end of the decade, which saw a transition back to the steady-state regime and house price growth slowed. From then on, house prices continued to grow steadily, averaging just over $1 \%$ per quarter until the turn of the decade. Following the collapse of the tech bubble at the end of the 1990s, policymakers reacted by adopting expansionary monetary actions. This involved severe interest rate cuts, which made borrowing a lot cheaper than in previous years. Furthermore, deregulation meant that the securitization market grew significantly, making it easier for borrowers to obtain mortgages. House prices began rising faster than they had done at any time in the previous 40 years and there was a transition to the boom regime. Several papers including Shiller (2007), Coleman et al. (2008) and Nneji et al. (2013b), attribute this period's growth in prices to the existence of a speculative bubble in the market. A crash then followed this during $2000-2005$, which saw the biggest drop in house prices in recent history, and there was a meltdown in the mortgage market. Although there were two consecutive quarters in 2009 which saw real house prices grow by almost $5 \%$ combined, further dips occurred and the market soon reverted back to the crash regime. Table 4 provides the estimated parameters of the MS model which aims to provide a detailed insight into how these four economic variables influence the growth in house prices in the three regimes.

\section{Table 4: Markov Switching Model Output}

. This time series regression analysis is performed on the whole sample between 1960 and 2011. The dependent variable is the quarterly change in house prices and the independent variables are the changes in the short term interest rate $(\Delta \mathrm{SR})$, the term spread $(\Delta \mathrm{TS})$, inflation rates $(\Delta \mathrm{CPI})$, and disposable income $(\Delta \mathrm{INC})$. The figures in parentheses are the p-values and the grey shade indicates variables that are statistically significant (at the $10 \%$ level or better).

\begin{tabular}{cccccc}
\hline Regime & Constant & $\boldsymbol{\Delta S R}$ & $\boldsymbol{\Delta}$ TS & $\boldsymbol{\Delta}$ CPI & $\Delta$ INC \\
\hline \multirow{2}{*}{ Steady-State } & 0.0037 & -0.1165 & -0.0053 & -0.1431 & 0.1280 \\
& $(0.01)$ & $(0.00)$ & $(0.90)$ & $(0.00)$ & $(0.01)$ \\
\multirow{2}{*}{ Boom } & 0.019 & -0.1025 & -0.0928 & -0.2491 & 0.0028 \\
& $(0.00)$ & $(0.15)$ & $(0.08)$ & $(0.00)$ & $(0.96)$ \\
Bust & -0.0204 & -0.3961 & -0.2226 & -0.1785 & 0.2686 \\
& $(0.01)$ & $(0.30)$ & $(0.64)$ & $(0.68)$ & $(0.54)$ \\
\hline
\end{tabular}

From Table 4, there are clear differences in the signs, significances and sizes of the estimated betas depending on the regime. Note that the estimated coefficients are also standardised in order to enable us to easily compare the relative importance of each of the explanatory variables. For example, changes in the short term interest rate influence the housing market in the steadystate and boom regimes only. Focusing on the size of the coefficients, it is clear that interest rate cuts have a more severe effect on the growth of house prices in the steady-state regime than in any other regime. Similar to our finding from the linear model that the term spread influences growth of house prices, in the boom regime, an increase in the term spread or a widening of the 
gap between long and short term interest rates is expected to cause a fall in the growth rate of house prices, perhaps as a result of investors' expectations of future increases in the cost of borrowing. In the steady-state and crash regimes, the term spread has no effect on house price dynamics. However, unlike the linear model which depicted that the rate of inflation was statistically insignificant, we find that inflation does in fact have an effect on the growth of house prices in the boom and steady-state regimes. The last driving variable to be examined is disposable income growth. In the MS model, percentage changes in disposable income positively influence growth in house prices in the steady-state regime only.

\section{Is monetary policy a catalyst in instigating a switch from the crash regime?}

It is worth mentioning that the housing market becomes completely insensitive to changes in the economic variables in the crash regime; none of the variables are seen to have any effect on house price changes. Given these findings, it is clear that monetary variables affect the real estate market within a regime, but could policymakers instigate a transition from the crash regime to either the steady-state or a boom regime? In order to answer this question, we employ a probit model. We observe the filtered probabilities generated from the estimation of the MS model, focusing on the probability of being in the crash regime. The probit model is a binary specification, and thus we assign $1(y=1)$ if the observed filtered probability $\left(y^{*}\right)$ of being in the crash regime is greater than 0.33 (as there are three regimes) and 0 otherwise - i.e., the left hand variable of the probit model, $y$, equals 1 if the probability of being in the bust regime is greater than $33 \%$. This allows us to examine whether monetary policy tools such as the short term interest rate, the term spread and the level of money supply (M2) could be used by policymakers to instigate a switch away from the crash regime. We also include a macroprudential tool available to policymakers - the loan-to-income ratio. Here, "loan" refers to the home mortgage debt outstanding in the economy. This is a leverage proxy used in measuring how easy it is to obtain credit, whereby a high ratio represents easy credit conditions. Thus in this section, we measure how alterations to these policy tools could reduce the probability of being in the crash regime. The probit model is as follows:

$$
\operatorname{Pr}\left(y^{*}>0.33\right)=\operatorname{Pr}(y=1 \mid x)=F\left(\alpha_{0}+\alpha_{1} \text { dummyLTI } I_{t-1}+\alpha_{2} \text { dummySR } R_{t-1}+\alpha_{3} d u m m y M S_{t-1}+\alpha_{4} d u m m y T S_{t-1}\right)
$$

where dummyLTI, dummySR, dummyMS and dummyTS refer to dummy variables which assign 1 when there are increases in the loan-to-income ratio, short term interest rate, money supply or term spread, respectively and 0 when there are no changes or decreases occur. 
In this probit model, $F($.$) follows a cumulative normal distribution:$

$$
F(x)=\Phi(x)=\int_{-\infty}^{x} \phi(z) d z
$$

where the normal density function, $\phi(z)$, is given by:

$$
\phi(z)=\frac{\exp \left(-\frac{z^{2}}{2}\right)}{\sqrt{2 \pi}}
$$

A statistically significant positive $\alpha_{i}(i=1,2,3)$ would imply that an increase in the value of one of these monetary tools would increase the probability of remaining in the crash regime in the next quarter whilst a negative $\alpha_{i}$ that is statistically significant implies the reverse. This part of the study provides information as to whether monetary policy approaches may be suitable for periods of severe downturns in the housing market. The results of the probit regressions are reported in Table 5.

\section{Table 5: Probit Model Output (Including LTI)}

We present the probit model parameter estimates as stated in equation (9). The figures in parentheses are p-values and the grey shade indicates variables that are statistically significant (at the $10 \%$ level or better). The McFadden and Estrella R-squared figures for these probit maximum likelihood estimates are 0.03 and 0.02 , respectively.

\begin{tabular}{cccccc}
\hline & Constant & dummyLTI & dummySR & dummy TS & dummyMS \\
\hline \multirow{2}{*}{$\alpha$} & -1.1281 & -0.0998 & 0.1410 & 0.4212 & -0.2015 \\
& $(0.00)$ & $(0.65)$ & $(0.55)$ & $(0.07)$ & $(0.39)$ \\
\hline
\end{tabular}

It is immediately obvious from Table 5 that, apart from the intercept, only one variable, the term spread, has a statistically significant parameter estimate. This implies that changes to short term interest rate levels and the money supply would have no effect on forcing the housing market away from the crash regime. Therefore, in times of significant crashes in the housing market as recently witnessed, money supply increases or short term interest rate cuts would not be sufficient to encourage a switch away from this regime. The coefficient representing the term spread, on the other hand, is positive and statistically significant, thus implying that an increase in the term spread would increase the probability of remaining in the crash regime. Therefore, a decrease in the spread would reduce the probability of being in the crash regime, thereby increasing the probability of switching to either a boom or a steady-state regime. This means that the interest rate spread may contain relevant forward-looking information about the future housing cycle beyond the information contained in the money supply and short term interest rates. Our finding is consistent with those in the economic literature postulating the effectiveness 
of the yield spread in predicting future economic activities and business cycles. Many of these papers have found the interest rate spread to be the leading indicator of business cycles. For example, Estrella and Hardouvelis (1991) demonstrate the usefulness of the spread between the 10-year Treasury bond rate and the 3-month T-bill yield in predicting the probability of a recession in the US since 1950. Also, Haubrich and Dombrosky (1996) find that the term spread is an efficient forecaster of economic growth up to four quarters ahead. Other papers to have investigated the predictive content of yield spreads in forecasting business cycles include Dueker (1997), Estrella and Mishkin (1998), Dotsey (1998) and Hamillton and Kim (2000).

Policymakers may rely on other housing-specific non-monetary policy tools in dealing with real estate busts. Crowe et al. (2011) evaluate the effect of macroprudential regulations and fiscal as well as monetary policies in dealing with real estate market booms rather than busts. They note that monetary policy changes may not be the most efficient way to influence the real estate market because these changes would affect other relevant economic factors such as the level of unemployment. Their study highlights possibilities that fiscal policy approaches, such as alterations to taxes on homeownership, could be effective in taming exuberance in the property market. They argue that other fiscal tools could include changes to housing transactions tax rates and mortgage interest tax deductibility. Crowe et al. also show that macroprudential rules, such as strict limits on loan-to-value ratios, also work in reducing house price booms. Given their findings, it may be possible that prudent property tax rate cuts and increased loan-to-value ratios may help the real estate market move away from the crash regime without having a significantly huge effect on other aspect of the economy. It would also be of interest to investigate the influence of fiscal tools on the regime transitions, but the lack of availability of quarterly information dating back to 1960 makes it impossible to statistically test this.

\section{Conclusions}

In this paper, we employ a three-state Markov switching nonlinear econometric model to examine the relationship between the residential real estate market and key macroeconomic variables in the US. We investigate the regime-dependent effects of changes to short term interest rates, term spread, inflation and GDP on house prices - i.e., we study the effect of these macroeconomic variables on house price dynamics in times of housing booms, busts and tranquility. The paper then proceeds to evaluate the effect of policy changes on switching regimes in the housing market. We find the following. First, there is statistical evidence to suggest there to be three distinct regimes in the housing market, namely "steady-state", "boom" 
and "crash" regimes. Changes to the selected macroeconomic variables significantly affect the dynamics of house prices in the steady-state and boom regimes only. During housing busts, however, the real estate market disconnects from these macroeconomic fundamentals. We also find evidence of varying degrees of sensitivity of house prices to changes in these economic variables, with prices generally being more sensitive during housing booms. We also show that using a standard, single-state methodology inappropriately indicates that house prices are responsive to changes in the short term interest rate and GDP only, thus providing an incomplete view of the market.

Our second set of key findings in this study is based on the estimated probabilities of switching from one regime to another. We find that there is a $5 \%$ chance of moving from a housing boom in one quarter to a housing bust in the next quarter, but the most persistent regime is the steadystate as there is a $98 \%$ chance of remaining within it if the housing market was previously in the steady-state. Third, we show that monetary policy could potentially be used as a tool to enforce a switch away from housing busts. Using a probit model based on the estimated filtered probabilities from the Markov switching model, we find there is a statistically significant and positive relationship between increases in the term spread and the probability of being in the housing crash regime, thus implying that a reduction in the spread between long and short term interest rates reduces the probability of being in the crash regime. Interest rates and money supply cannot, however, be used to instigate a switch away from a housing bust.

Although this study provides a detailed examination of the impact of macroeconomic fluctuations on the housing market, we do not evaluate the effect of other non-monetary policy changes on the market due to data constraints, and thus further research could be conducted in this area. If researchers were able to access unique fiscal data, they could extend this study to investigate whether it is possible to use fiscal policies to enforce a transition away from housing busts. This would allow policymakers to judiciously select the most appropriate tools to use in reinvigorating a collapsing real estate market or possibly dampening demand during times of overheating. 


\section{REFERENCES}

Abraham, J.M. and Hendershott, P.H. 1992. Patterns and determinants of metropolitan house prices, 1977 to 1991, In Lynn E. Browne and Eric S. Rosengren, (eds.), Real Estate and the Credit Crunch, Boston, M.A: Federal Reserve Bank of Boston, 18 - 42.

Adams, Z., and Füss, R. 2010. Macroeconomic determinants of international housing markets, Journal of Housing Economics, 19, 38 - 50.

Baffoe-Bonnie, J. 1998. The dynamic impact of macroeconomic aggregates on housing prices and stock of houses: A national and regional analysis, Journal of Real Estate Finance and Economics, $17,179-97$.

Beltratti, A. and Morana, C. 2009. International house prices and macroeconomic fluctuations, Journal of Banking and Finance, 34, 533 - 45.

Bouchouicha, R. and Ftiti, Z. 2012. Real estate markets and the macroeconomy: A dynamic coherence framework, Economic Modelling, 29, 1820 - 29.

Bring, J. 1994. How to standardize regression coefficients, The American Statistician, 48, 209-13.

Brooks C and Tsolacos, S. 1999. The impact of economic and financial factors on UK property performance, Journal of Property Research, 16, 139 - 52.

Brunnermeier, M.K. and Julliard, C. 2008. Money illusion and housing frenzies Review of Financial Studies, 21, $135-80$.

Case, K., Quigley, J. and Shiller, R. 2001. Comparing wealth effects: the stock market versus the housing market, NBER Working Paper Series, No. 8606.

Coleman IV, M., LaCour-Little, M. and Vandell, K. 2008. Subprime lending and the housing bubble: Tail wags dog?, Journal of Housing Economics, 17, 272 - 90.

Crowe, C., Dell'Ariccia, G., Igan, D. and Rabanal, P. 2011. How to deal with real estate booms: Lessons from country experiences, IMF Working Paper, No. 11/91.

Davis, M.A., Lehnert, A. and Robert, F.M. 2008. The rent-price ratio for the aggregate stock of owneroccupied housing, Review of Income and Wealth, 54, 279 - 84.

Dotsey, M. 1998. The predictive content of the interest rate term spread for future economic growth, Federal Reserve Bank of Richmond Quarterly, 84, 31 - 51.

Dueker, M.J. 1997. Strengthening the case for the yield curve as a predictor of U.S Recessions, Federal Reserve Bank of St. Louis Review, 79, March/April, 41 - 51.

Englund, P. and Ioannides, Y.M. 1997. House price dynamics: An international empirical perspective, Journal of Housing Economics, 6, 119 - 36.

Estrella, A. and Hardouvelis, G.A. 1991. The term structure as a predictor of real economic activity, Journal of Finance, 46, $555-76$. 
Estrella, A. and Mishkin, F.S. 1998. Predicting US recessions: Financial variables as leading indicators, Review of Economics and Statistics, 80, $45-61$.

Ghent, A.C. and Owyang, M.T. 2010. Is housing the business cycle? Evidence from U.S. cities, Journal of Urban Economics, 67, 336 - 51.

Glindro, E.T., Subhanij, T., Szeto, J. and Zhu, H. 2011. Determinants of house prices in nine Asia-Pacific Economies, International Journal of Central Banking, 3, 163 - 204.

Guidolin, M. and Timmermann, A. 2008. Asset allocation under multivariate regime switching, Journal of Economic Dynamics and Control, 31, 3503 - 44.

Hall, S., Psaradakis, Z. and Sola, M. 1997. Switching error-correction models of house prices in the United Kingdom, Economic Modelling, 14, 517 - 27.

Hamilton, J.D. 1989. A new approach of the economic analysis of nonstationary time series and the business cycle, Econometrica, 57, 357 - 84.

Hamilton, J.D. 1994. Time series analysis. Princeton University Press, Princeton, NJ.

Hamilton, J.D. and Kim, D.H. 2000. A re-examination of the predictability of economic activity using the yield spread, NBER Working Paper Series, No. 7954.

Haubrich, J.G. and Dombrosky, A.M. 1996. Predicting real growth using the yield curve, Federal Reserve Bank of Cleveland Economic Review, 32, 26-35.

Himmelberg, C., Mayer, C. and Sinai, T. 2005. Assessing high house prices: Bubbles, fundamentals and misperceptions, Journal of Economic Perspectives, 19, 67 - 92.

Holly, S. and Jones, N. 1997. House prices since the 1940s: Cointegration, demography and asymmetries, Economic Modelling, 14, 549 - 65.

Hort, K. 1998. The determinants of urban house price fluctuations in Sweden: 1968 - 1994, Journal of Housing Economics, 7, 93 - 120.

Iacoviello, M. and Minetti, R. 2003. Financial liberalization and the sensitivity of house prices to monetary policy: Theory and evidence, Manchester School, 71, 20 - 34.

Kim, C.J. 1994. Dynamic linear models with markov-switching, Journal of Econometrics, 60, 1 - 22.

Lastrapes, W.D. 2002. The real price of housing and money supply shocks: Time series evidence and theoretical simulations, Journal of Housing Economics, 11, 40 - 74.

Levin, E.J. and Wright, R.E. 1997. The impact of speculation on house prices in the United Kingdom, Economic Modelling, 14, 567 - 85.

Ling, D. and Naranjo, A. 1999. The Integration of Commercial Real Estate Markets and the Stock Market. Real Estate Economics, 27, 483 - 516.

McQuinn, K. and O'Reilly, G. 2008. Assessing the role of income and interest rates in determining house prices, Economic Modelling, 25, 377 - 90. 
Nneji, O., Brooks, C. and Ward, C. (2013a). Commercial real estate and equity market bubbles: Are they contagious to REITs? Urban Studies, forthcoming.

Nneji, O., Brooks, C. and Ward, C. (2013b). Intrinsic and rational speculative bubbles in the US housing market: 1960 - 2011, Journal of Real Estate Research, forthcoming.

Ortalo-Magne, F. and Rady, S. 2006. Housing market dynamics: On the contribution of income shocks and credit contraints, Review of Economic Studies, 73, 459 - 485.

Ryden, T., Terasvirta, T. and Asbrink, S. 1998. Stylized facts of daily return series and hidden markov model, Journal of Applied Econometrics, 13, 217 - 244.

Shiller, R. 2007. Understanding recent trends in house prices and home ownership, NBER Working Paper Series, No. 13553.

Tsatsaronis, K., and Zhu, H. 2004. What drives housing price dynamics: Cross-country evidence, BIS Quarterly Review, $65-78$.

Whaley, R.E. 2000. The investor fear gauge, Journal of Portfolio Management, 26, 12 - 17.

Wheelock, D.C. 2006. What happens to banks when house prices fall? U.S. regional housing busts of the 1980s and 1990s, Federal Reserve Bank of St. Louis Review, 413 - 28.

Xiao, Q. 2007. What drives Hong Kong's residential property market - A Markov switching present value model, Physica A, 383, $108-14$. 